\title{
Robert W. Fulton, 1914 to 2004
}

\author{
Paul Williams and Luis Sequeira
}

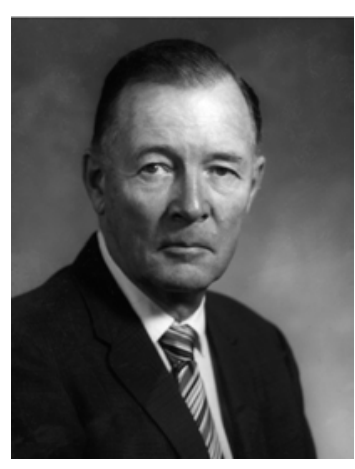

With the death of Robert W. Fulton on 7 January 2004, the Department of Plant Pathology at the University of Wisconsin-Madison lost one of its most distinguished emeritus faculty members. He was also one of the last of the great generation of plant pathologists who, beginning in the 1930s, provided the foundations for plant virology. That field has remained one of the most active areas of scientific research, due in part, to the early efforts of scientists like Professor Fulton. He was able to isolate, purify, and determine the properties of plant viruses purely on the basis of local lesion assays and the use of equipment that by today's standards would be considered rudimentary. He became one of the world's experts on stone-fruit viruses, which are notoriously difficult to isolate because of their instability. For decades, he provided antisera freely to other scientists for use in identification work.

Professor Fulton was born on 28 January 1914, in Sisterville, WV, but his family moved to Wisconsin when he was a child. He graduated from Viroqua High School in 1931 and obtained an A.B. in botany from Wabash College in 1935. His graduate studies were at the University of Wisconsin, where he obtained a Ph.D. degree in 1940. His initial professional career was in the Department of Horticulture at the University of Wisconsin, where he became an expert on tobacco diseases. That career was interrupted by World War II, and he was proud to have served his country from 1942 to 1946 as a First Lieutenant in the U.S. Army. He was appointed to the Department of Plant Pathology in 1947, where he established a world-class program on stone-fruit viruses until his retirement in 1984. He published more than 125 research papers on numerous aspects of viruses, including isolation, structure, properties, and transmission. In 1970, Dr. Fulton was elected Fellow of The American Phytopathological Society (APS) in recognition of his contributions to the field of plant virology.

Professor Fulton had a very productive career as a scientist, a teacher and mentor of graduate students, and a distinguished editor of scientific journals. He was a quiet, reserved man, who preferred to work alone and had no patience with ordinary chitchat or gossip. A man of few words, he was, nevertheless, a demanding, punctilious editor who had intimate knowledge of the
English language. An avid sportsman, his quiet demeanor would change to excitement only when describing his fishing or hunting adventures. An expert lapidary, he could cut and polish precious stones in a highly professional fashion, one of several hobbies that helped him face retirement when that dreaded day arrived.

Professor Fulton was a prodigious worker and rigorous scientist. He could spend endless hours in the laboratory or the greenhouse, intensely devoted to the task at hand and oblivious of the noise and activities around him. Quiet competence are words that one associates with Bob's professional life. Many of his colleagues remember that in the early 1960s the lights in his office always seemed to be on at night, where he was continuously editing manuscripts for Phytopathology and single-handedly proofreading and publishing the journal (editorial board, 1958 to 1960; editor-in-chief, 1961 to 1963). Nowadays, the same work is done by a large APS staff at St. Paul and a long list of associate and senior editors that make that job of the editor-in-chief much easier. During his career, Bob was an editor of Virology (1965 to 1970) and a member of many other editorial committees, including that which involved preparing the Golden Jubilee Volume (Plant Pathology: Problems and Progress, 1908-1958), a book that remains a landmark in our professional development. He was a contributor to numerous books on plant virology and was a frequent reviewer of this field in the Annual Review of Phytopathology. Significantly, Bob also took the time to write about the life of his mentor, James Johnson, and to describe the unusual role of Wabash College, his alma mater, as a source of numerous distinguished plant scientists.

Bob taught the departmental course in plant virology for many years, but his impact as a teacher was mainly as a mentor of graduate students. The fact that most of the graduate students who completed their Ph.D. degrees under his direction have gone on to distinguished careers is probably the best testimony of Professor Fulton's lasting influence in the field of virology.

Bob was happily married to his wife Jeanette for 29 years. He maintained close ties with his family, particularly his brother Joe, a distinguished plant pathologist at the University of Arkansas for many years, who survives him. We cannot complete this account without mention of Bob's love of dogs. He enjoyed having a pet dog nearby throughout his life and it seems totally fitting that, as his wife describes it, he died while rocking peacefully with a dog on his lap.

Publication no. P-2004-0617-010 